\title{
LAS COMUNIDADES DE MONTES EN GUIPÚZCOA EN EL TRÁNSITO DEL MEDIEVO A LA EDAD MODERNA
}

\author{
ÁlVARO ARAGÓN RUANO \\ Universidad del País Vasco
}

El de las Comunidades de Montes es un fenómeno que ha estado y está muy presente en la realidad histórica de Guipúzcoa. Responde a un régimen de propiedad comunal atípico ${ }^{1}$, y en él se englobaría un amplio abanico de fórmulas que atienden al título de Montes comunes o Comunidades de montes propiamente dichas, Montes proindivisos, Montes Francos y Parzonerías. La particularidad de estas fórmulas reside en que el disfrute no pertenece al conjunto de habitantes de un solo pueblo o villa, sino a los vecinos y moradores de varios pueblos, bien de la misma provincia, bien con pueblos de provincias vecinas y limítrofes, quienes como parzoneros o parcioneros gestionan y disfrutan los montes de una forma comunitaria, aunque proporcional, en función de una serie de criterios establecidos generalmente tras la firma de una concordia. Según algunos autores, a diferencia de los montes concejiles, en las comunidades de montes la propiedad recaía en las entidades concejiles, no en los vecinos, aunque el aprovechamiento fuese comunal ${ }^{2}$.

En Guipúzcoa, durante la Baja Edad Media y la Edad Moderna, la titularidad de los montes estuvo en manos de particulares o del conjunto de vecinos y moradores de las entidades municipales. En el caso de la titularidad particular, obtenida por compra,

1. NIETO, Alejandro: Bienes comunales, Madrid, 1964, p. 389.

2. En torno a esta cuestión, hay un cierto debate entre quienes, como Asunción Urzainqui, consideran que la propiedad de los montes recae en los concejos, mientras que el uso en los vecinos y moradores, y quienes, como Lourdes Soria Sesé, no lo tienen tan claro, pues dudan del verdadero significado de los conceptos «concejo», «lugar» y «vecindades», utilizados en la documentación, conceptuándolos, no como una entidad abstracta, sino como el conjunto de vecinos constituidos asambleariamente, a quienes pertenece la facultad de disposición sobre los montes (URZAINQUI MIQUELEIZ, Asunción: Comunidades de montes en Guipúzcoa: las parzonerías, San Sebastián, 1990, p. 31; SORIA SESÉ, Lourdes: «Bienes comunales en Navarra y las Provincias Vascas (siglos XVI-XVIII)», DE DIOs, Salustiano (Dir.): Historia de la propiedad en España. Bienes comunales, pasado y presente, Madrid, 2002, p. 113). 
donación o abolengo, los propietarios ejercían sus derechos de uso y aprovechamiento de forma plena, pero siempre en el marco de las disposiciones legales municipales, forales o reales. En el caso de los montes concejiles, surgidos por cesión real, compra del realengo o del señorío, o por el asentamiento de un grupo humano, la titularidad correspondía a la propia comunidad de vecinos y moradores.

En este segundo caso, los bienes concejiles, es decir, aquellos que pertenecen a un concejo, están formados por bienes comunales o de aprovechamiento común, bienes de propios y baldíos. Los bienes comunales o de aprovechamiento común son aquellos que pueden ser disfrutados por los vecinos y moradores de un lugar libremente. Los bienes de propios, sin embargo, son patrimonio del concejo y su aprovechamiento no es libre. Los propios son aquellos bienes que se reserva el concejo para hacer frente a sus gastos, mediante su arrendamiento o venta. En este caso, el uso y aprovechamiento se extiende también a compradores y arrendadores foráneos, por supuesto a cambio de un canon. Son por tanto terrenos y bienes concejiles en los que los vecinos no tenían aprovechamiento alguno, pues los concejos vendían los productos forestales en almoneda o arrendaban su usufructo; por tanto, el dominio y la propiedad eran del concejo y el uso restringido o «acotado». Los baldíos eran terrenos vacantes, cuya titularidad no correspondía a los concejos, sino al monarca, aunque la diferencia con las tierras de aprovechamiento común era muy vaga ${ }^{3}$.

En palabras de Rosa Ayerbe, en los bienes comunales los propietarios son todos los miembros de la comunidad, indivisamente, aunque deben cumplir dos condiciones. En primer lugar, que el uso y disfrute sea de los individuos que conforman la colectividad, no de la persona social, como ocurre en los bienes de propios. En segundo lugar, los bienes comunales deberán permanecer unidos a la colectividad, sin que puedan ser destruidos o enajenados ${ }^{4}$. No obstante, durante la Baja Edad Media y la Edad Moderna, la entidad municipal aparece, al menos de forma teórica, como un órgano de actuación de la comunidad de vecinos y moradores, es decir, como instrumento de la propiedad colectiva en manos de la colectividad. Sin embargo, a partir del siglo XV, con el inicio del progresivo cerramiento y oligarquización de los concejos -gracias a la acción de los juristas, basados en el derecho romano-, entre la comunidad de habitantes y sus propiedades colectivas se va a interponer el concejo, como entidad sustantiva, no como simple expresión de la comunidad vecinal, que comenzará a regular el uso y aprovechamiento de los bienes comunales a expensas de los intereses de los concejantes,

3. VASSBERG, David: La venta de tierras baldías. El comunitarismo agrario y la corona de Castilla durante el siglo XVI, Madrid, p. 33 y ss.

4. AYERBE IrIBAR, María Rosa: «La Unión o Mancomunidad de Enirio y Aralar. Un caso modélico de montes comunales intervenidos por el Servicio Forestal de la Diputación de Gipuzkoa», Boletín de la Real Sociedad Bascongada de Amigos del País (BRSBAP), LXI, 2005-1, p. 6. 
quienes paulatinamente irán usurpando porciones de bienes comunales para convertirlos en bienes de propios 5 .

Por otro lado, los bienes comunales son en teoría inalienables, siendo necesaria la licencia real para proceder a su enajenación. Es este un aspecto interesante en el que creemos necesario detenernos, puesto que existen diversas posturas. Lourdes Soria considera que la ruptura de la inalienabilidad por licencia regia, no deriva, en última instancia, de que el rey sea el propietario de los bienes comunales sino de su papel de tutor de la colectividad. La concesión de la mencionada licencia no se debe entender como un reconocimiento a un posible derecho de propiedad del rey, sino al ejercicio de su acción de tutoría de la colectividad, como señor de la jurisdicción que se ejerce y se ha de ejercer sobre dichos bienes. Cuando los concejos realizan actos de disposición sobre los comunales no consideran que lo hacen porque estén disfrutando de un derecho permitido o tolerado por su legítimo titular, es decir, el monarca o el señor, sino porque están ejercitando un derecho propio, independientemente de que como personas morales los concejos estén sometidos a la tutela del monarca, en cuanto señor de la jurisdicción, y precisen por consiguiente de habilitación para realizar ciertas operaciones jurídicas, como enajenar sus bienes ${ }^{6}$.

Por su parte, Joaquín Salcedo Izu, remonta la titularidad del monarca, por derecho de conquista, a la época de la reconquista; en un principio, todo el territorio ocupado o el reino era patrimonio del rey. La propiedad particular surgió por concesión real y la gran propiedad nobiliaria y eclesiástica por concesiones, donaciones, compras y permutas. Con la aparición de las villas y su consiguiente dotación comunal de términos, se comenzó a regular el uso del bosque. En palabras del mismo, a través de las mencionadas vías, "la mayor parte de la propiedad de realengo fue cedida como término municipal a las villas que, en adelante, lo consideraron ejido común para sus habitantes. La dejación de estos términos de realengo hecha a las villas, en el momento de su fundación, consistía más en un usufructo que en una propiedad.»?.

En la práctica jurídica de la época no parecía estar tan claro, puesto que la propia doctrina contemporánea se caracteriza por cierta ambigüedad, estando sometida la legislación a diferentes interpretaciones y dando lugar a dispares $\mathrm{y}$, a veces, contradictorias resoluciones judiciales. Cabría recordar que en la práctica durante este período la distancia entre el patrimonio público y el patrimonio regio era muy sutil. En el caso de los montes de Encia, Ubarrundia, Alzania y Urbía, de realengo, el concejo de Salvatierra, que en 1418 mandó derribar los mojones que había ordenado colocar Pedro de Guevara, señor de Oñate, aseguraba que eran «de nuestro señor el rey e so

5. ARAGÓN RUANO, Alvaro: El bosque guipuzcoano en la Edad Moderna: aprovechamiento, ordenamiento legal y conflictividad, Donostia, 2001, pp. 91-97; GARCÍA DE ENTERRÍA, Eduardo: Las formas comunitarias de propiedad forestal y su posible proyección futura, Santander, 1986, p. 15.

6. SORIA SESÉ, Lourdes: «Bienes comunales...op. cit., pp. 111-114.

7. SALCEDO IZU, Joaquín: «Derecho forestal: conceptos e historia», AYERBE IRIBAR, María Rosa: Estudios histórico jurídicos. I. Estudios dedicados a la memoria del profesor L.M. Díez de Salazar Fernández, Bilbao, 1992, p. 913. 
la su merced de los comarqueros de ellos en comun $»^{8}$. Es curiosa, pero sintomática, esta afirmación por parte del concejo de Salvatierra, puesto que en 1401 los montes de Urbía ya habían sido donados por Enrique III a Fernán Pérez de Ayala, Merino Mayor y Corregidor de Guipúzcoa, en pago de sus servicios, y éste los vendió a la villa de Segura en junio de ese mismo año, por 500 florines de oro de Aragón y dos piezas de paño; la compra, confirmada en Valladolid en 1406, incluía montes y tierras que venían disfrutando desde hacía tiempo los alaveses ${ }^{9}$. A pesar de la firma de la concordia de 1430 entre alaveses y guipuzcoanos, por la que se formó la Parzonería Mayor de Álava y Guipúzcoa, no consta que los alaveses abonaran cantidad alguna a guipuzcoanos o al rey, no obstante lo cual, considerarán probado su derecho al disfrute de los mencionados montes.

Más aún, un siglo atrás, en 1290 Sancho IV ordenaba a todos los hidalgos de Guipúzcoa, que los pobladores de Segura no fuesen molestados en el disfrute de los bienes propios que tenían antes de ir a la puebla, fundada en 1256, y en el aprovechamiento de los montes, pastos y aguas del realengo "E uso bien sabedes que yo parte he en los montes e en los pastos e en las aguas e en los caminos, e nunca partiestes conmigo porque los mis pobladores no se sieruan dello asi como uso...E otrosi que se sieruan de los mis montes e de los pastos e de las aguas e de los exidos e de los caminos, guardando los mis derechos que yo deuo ayer ${ }^{10}$. De hecho, según José Luis Orella, con la creación de las villas desde finales del siglo XII, el rey quiso demostrar y reafirmar su derecho de realengo en todo el territorio de Guipúzcoa, que era lugar de donaciones episcopales y abadengos. La fundación de villas y el asentamiento del realengo comportaban la disminución del abadengo y del solariego, y esto a la larga favoreció la expansión de una clase social, urbana y manufacturera, exportadora y mercantil, contrapunto interesante para el control de la nobleza. La creación de villas en realengo comportaba la determinación de unos impuestos y de unos oficiales reales, como prestameros y recaudadores, merinos o «seniores civitatis» que engrosarían el poder económico y jurídico del rey. Además, en el caso de Guipúzcoa, como afirma el mencionado autor, prácticamente todo el territorio quedó en manos del realengo, por quedar bajo el control de la jurisdicción urbana de las diversas villas, si exceptuamos el señorío de Oñate y las tres alcaldías mayores de Sayaz, Aiztondo y Areria ${ }^{11}$.

8. Goicolea Julián, Francisco Javier: Archivo Municipal de Salvatierra-Agurain, Tomo II (1401-1450), Donostia, 1998, pp. 77-80.

9. Archivo de la Parzonería (A.Parz.), A, 1, 1 / 1. Véase ARAGÓN RUANO, Álvaro: «Gestión, uso y aprovechamiento de comunales y parzonerías en la Edad Moderna: el ejemplo de Entzia y de Urbía», PASTOR DíAZ DE GARAYO, Ernesto (Coord.): La llanada oriental a través de la historia; claves desde el presente para comprender nuestro pasado, Vitoria, 2003, p. 84.

10. Martínez DíEz, Gonzalo, Martínez DíEz, Emiliano, Martínez Llorente, Félix: Colección de documentos medievales de las villas guipuzcoanas (1200-1369), San Sebastián, 1991, p. 63

11. ORella UnZUe, José Luis: «Régimen municipal en Guipúzcoa en los siglos XIII y XIV», Lurralde, 2 (1979) (versión electrónica), p. 6. 
Está claro que con el paso del tiempo, lo que fue una graciosa merced pasó a ostentar título de propiedad -sobre todo tras la firma y confirmación de concordias y convenios, por tanto, a partir de los siglos XIV, XV y XVI-. A pesar de ello, seguimos pensando, como ya lo hemos manifestado en otras ocasiones, que, en la práctica, la titularidad última de los montes -atendiendo precisamente al hecho de que las villas se habían fundado en realengo-, si se prefiere por razón de jurisdicción, bien público, razón de Estado o de cualquier otra fórmula, o al menos la decisión última sobre el destino de los montes, era de la Corona, que así lo conceptuará y reclamará en numerosas ocasiones, lo que explica su actuación con respecto, por ejemplo, a los montes de Marina durante toda la Edad Moderna ${ }^{12}$.

Como bien nos demuestra Salustiano de $\operatorname{Dios}^{13}$, los juristas castellanos de finales del siglo XV y mediados del siglo XVII manejaban una gran cantidad de tópicos jurídicos, en torno a la adquisición, enajenación y, en fin, la propiedad sobre los comunales. Los titubeos de los autores y las divergencias entre ellos eran consecuencia de la versátil realidad de su tiempo, tan alejada de los orígenes, y de la necesidad de atender y aunar numerosos y variados intereses. En cuanto a la adquisición, consideran que de derecho nada corresponde a las ciudades a no ser que se le conceda por ley, costumbre o disposición de los hombres, por lo que han de probar su título, pues en principio todos los campos y tierras del reino de Castilla se presume que son del rey. Así mismo hacen hincapié en la libre asignación y destino a concejos, villas y fortaleza de términos y tierras por parte del rey, a quien correspondían por derecho de conquista, ya que los liberó de manos de los enemigos, de tal modo que en sus representaciones doctrinales otorgan

12. Aragón RuANO, Álvaro: El bosque guipuzcoano...op. cit., pp. 47-48. La propia Lourdes Soria Sesé nos presenta un caso que, en nuestra modesta opinión, es lo suficientemente equívoco como para no ser tan rotundo y maximalista en las afirmaciones que se vierten sobre a quién corresponde el dominio y la propiedad. La autora describe la actuación real al crear en el siglo XVI la Legua Acotada, pese a encontrase en términos propiedad de Eugui. Asegura que su alcance se recorta, pues el aprovechamiento no va a ser privativo del dueño de las herrerías, sino que corresponde a su naturaleza de terreno de propiedad concejil «acotado», de modo que los pueblos propietarios podrán disfrutarlo para su abastecimiento y uso propio (SORIA SESÉ, Lourde: «Bienes comunales...op. cit., pp. 126-127). Varias son las cuestiones que llaman poderosamente la atención. Primero, a pesar de la propiedad de Eugui, el rey tiene la potestad de crear un espacio acotado. Segundo, los tribunales vedan el aprovechamiento a ambas partes. Tercero, todas las partes reclaman la propiedad de los montes; lo cual demuestra que muy claro no debía estar, porque todos albergaban esperanzas de que les fuera confirmada a su favor. Cuarto, no se pone en cuestión la venta realizada por el rey al dueño de las herrerías; como en el caso de otras comunidades, por ejemplo, las Parzonerías guipuzcoanas, a pesar de la venta, el rey y el comprador estaban obligados a respetar el derecho al uso de los habitantes de esos territorios. Lo mismo ocurrirá por ejemplo en el caso de las enajenaciones realizadas desde el siglo XVIII sobre terrenos comunales, cuyos nuevos propietarios deberán respetar los derechos ganaderos de paso de los vecinos. No nos parece, por tanto, que sea tan clara la propiedad de los concejos. Una de las principales alegaciones de los concejos para demostrar su propiedad sobre los comunales era la de la posesión inmemorial, cuando sabemos que, al menos en el caso guipuzcoano, su adjudicación tomará cuerpo legal a partir de la concesión de cartas-puebla por parte, precisamente, de los monarcas.

13. DE Dios, Salustiano: «Doctrina jurídica castellana sobre adquisición y enajenación de los bienes de las ciudades (1480-1640)», DE Dios, Salustiano (Dir.): Op. cit., pp. 15-79. 
los juristas suma importancia a la concesión y destinación regia de los términos concejiles, al momento anterior y posterior a la misma, y sus consecuencias; principio, como se ha mencionado, derivado de la potestad del rey para dividir términos, provincias y villas, por ostentar la jurisdicción, protección y defensa. Las posiciones de los juristas varían de forma ostensible: unas más favorables a las ciudades y sus vecinos y otras al rey. En la mayoría de los casos se admite que la propiedad y el dominio corresponden a las ciudades, siendo del rey la jurisdicción, aunque curiosamente sólo en el caso de los bienes comunes y de propios, pues los baldíos se adjudican a la propiedad del rey. Pero no todos son de la misma opinión. Así Bartolomé de Humada, quien incurre en ostensibles contradicciones, sostiene que tanto en los bienes comunes en uso y utilidad como en los propios del concejo el dominio directo corresponde al rey y el útil a las ciudades. Recuerda que fue el rey quien concedió los límites de las ciudades y quien asignó y donó las tierras que le pertenecían por la guerra, o, con un sentido más amplio, que la ciudad o castro nada corporal tenía diputado de derecho a no ser cuanto por ley, costumbre o disposición de los hombres le fuese designado.

En cuanto a la enajenación, existían también una gran cantidad de elementos contradictorios. Los más prorregios sostuvieron que el monarca tenía el dominio sobre todo el territorio del reino, de manera que con causa podía proceder a la venta y enajenación de todas las tierras de las ciudades y, por supuesto, de los baldíos. Fue unánime la opinión en torno a la necesidad de la licencia regia para la enajenación de los bienes de uso común, pero más controvertida en el caso de los propios, aunque se coincidía en su conveniencia. Luis Velázquez de Avendaño llegó a poner en cuestión que las ciudades tuvieran dominio sobre sus bienes, incluso el útil, tanto sobre los de uso común como sobre los propios, y que por tanto dispusiesen de sus rentas libremente, puesto que adjudicaba el dominio al rey. Por su parte, Fernández de Otero, ante los debates de la doctrina ius commune, establece que si el litigio versa acerca del dominio y propiedad del pasto público, como atañe al monarca, verdadero señor del territorio, es imprescindible la licencia, mientras que si no es sobre el dominio y la propiedad, perjudicando únicamente a los vecinos y habitantes, no es necesaria la licencia.

En suma, es ésta una cuestión pantanosa y poco clara, pero que no sorprende teniendo en cuenta la lógica de funcionamiento de la época, que respondía a una perfecta lógica aristotélica y dialéctica, y que desde un punto de vista actual y presentista pueden resultar aparentemente contradictorias y jamás unívocas. ¿Hasta dónde llegaba el bien común y público?. Llegado el momento de enajenación, ¿qué era considerado comunal, propio o baldío, cuando, como ya se ha insinuado, quienes tomaban la decisión eran el monarca o las oligarquías locales, más pendientes de sus propios intereses que de los del común?

A pesar de las coincidencias entre los diferentes modelos de comunidades de montes, existen importantes diferencias. Los montes comunes, montes proindiviso, y montes francos son montes comunales cuya propiedad y, en consecuencia, aprovechamiento es compartido entre distintas corporaciones, es decir, cuya propiedad no es exclusiva de un sólo municipio, sino que se halla proindivisa o pertenece a varios pueblos. En este caso, si bien la participación es proporcional, generalmente en función 
del sistema de fogueraciones, las decisiones administrativas y económicas se toman de forma coordinada, de manera que ningún municipio ejerce un papel directivo ni asume la representación general, ni existen instituciones específicas que regulen la gestión. Pero este modelo de gestión no fue siempre así y se consolidó fruto de un largo proceso en el tiempo, no exento de conflictos durante la Baja Edad Media, obligando a las partes implicadas a llegar a convenios y concordias, que regularan el uso del bosque y los pastos.

Por su parte, las parzonerías son montes comunales poseídos proindiviso por cierto número de entidades municipales. El término «parzonería» tiene una doble acepción, geográfico-territorial e institucional ${ }^{14}$. Una parzonería es una asociación o agrupación de entidades que detenta de forma conjunta la propiedad de unos montes y ejerce, por tanto, mancomunadamente, el disfrute de los mismos. Pero por extensión, la parzonería será también el territorio o espacio objeto de aprovechamiento por parte de la mencionada comunidad o unión de pueblos. En resumidas cuentas, las parzonerías son las comunidades de montes de propiedad proindivisa de dos o más entidades locales. Aunque en la mayoría de los casos, y a diferencia del resto de comunidades, las parzonerías se referían sobre todo al disfrute de pastos, también organizaban el disfrute del bosque y de sus productos. Dentro de las parzonerías, así como en el resto de comunidades, existían bienes de aprovechamiento común y bienes propios, que se reservarán los concejos miembros de la comunidad para venderlos, arrendarlos y cubrir sus gastos y necesidades. A diferencia del resto de comunidades, en este caso sí existen municipios que ejercen un papel directivo y asumen la representación general, e instituciones específicas que regulan la gestión.

\section{LA INDEFINICIÓN TERRITORIAL Y JURISDICCIONAL DE LAS CARTAS- PUEBLA}

En las cartas-puebla concedidas a las diferentes entidades municipales que fueron surgiendo en Guipúzcoa desde finales del siglo XII hasta finales del siglo XIV, la Corona concedía a los habitantes de cada una de ellas un territorio concreto, aunque sin una delimitación bien definida, con sus montes, pastos y aguas. En el caso concreto de Guetaria, Alfonso VIII le donó en 1209 «ut illud perpetuo habeatis in montibus, pascuis, aquis et omnibus causis... $\rangle^{15}$. En 1294 Sancho IV erige la villa de Iciar y le otorga "los terminos e los montes e los rios e las fuentes e los pastos e los seles para sus ganados que nos auemos e deuemos auer» ${ }^{16}$. Por acotar en el tiempo este fenómeno, mencionaremos, por último, el caso de la carta de población otorgada en 1383 por Juan I a diversos moradores de Urrechu para fundar la villa de Villarreal, por la que les

\footnotetext{
14. Garayo Urruela, José María: «Las comunidades de montes de Álava», Narria: estudios de artes y costumbres populares, $\mathrm{n}^{\circ}$ 53-54 (Álava), p. 13.

15. Martínez DíEz, Gonzalo, Martínez DíEz, Emiliano, Martínez Llorente, Félix: Colección de documentos medievales... (1200-1369)...op. cit., p. 21.

16. Ibidem, p. 76.
} 
concedía un territorio limítrofe con Azcoitia, Azpeitia y Vergara «con todas sus tierras e pastos e prados e fuentes e exidos e aguas corrientes e non corrientes e con todos los otros derechos que han e les pertenece en cualquier manera .... ${ }^{17}$.

A medida que se fueron creando nuevas entidades en el territorio de otras ya constituidas o dentro de entidades más globales -como los valles-comenzaron a surgir los problemas. Esto ocurrirá a fines del siglo XIII, como dejan entrever los casos de Mondragón en 1280 y Segura en 1290. Concretamente, en 1280 Alfonso X concedió a los moradores de Mondragón el usufructo de los montes, pastos y ríos del realengo del valle de Léniz, que algunos hidalgos del mencionado valle trataban de impedir: «Seppades que los mios pobladores del mio conçeio de Mondragón, se me enbiaron querellar que los fijosdalgo del termino de Leniz razonauan muchos logares en termino de Leniz por suyos, asi en los rios commo en los montes e en los pastos e en los yssidos e en los otros logares que razonauan por sus heredamientos, ... $\rangle^{18}$. En todos los casos, la Corona intercede a favor de las nuevas villas y sus habitantes, para que «se sieruan de los mis montes e de los pastos e de las aguas e de los exidos e de los caminos, guardando los mis derechos que yo deuo auer» ${ }^{19}$.

Ello demuestra que la concepción geográfica que se tenía antes de la fundación de las villas era la que venía definida por los valles y era esa misma la que se aplicaba en lo referente al disfrute de los montes; es decir, probablemente antes del siglo XIII, los montes de cada valle únicamente podían ser aprovechados por sus habitantes, permaneciendo vedados a los del resto de valles ${ }^{20}$. Bajo esta premisa se entiende la concesión a Guetaria en el año 1270 de un privilegio por el cual sus vecinos podían cortar en los montes de Guipúzcoa toda la madera necesaria para hacer casas y navíos, puesto que "...dicen que non ge lo dexais cortar en los montes...»" ${ }^{21}$ o los fueros de ferrerías a los ferrones de Oyarzun e Irún-Iranzu en 1328, de Marquina de Suso en 1335 y su ampliación a la Merindad de Guipúzcoa en $1338^{22}$. Por ello, cuando se instalan las villas, el resto de habitantes de los valles - principalmente hidalgos- ven lesionados sus derechos de uso y aprovechamiento, y pretenden seguir ejerciéndolos, provocando la fricción que se traduce en una serie de supuestas usurpaciones y pleitos, que con el tiempo obligarán a la firma de concordias y confirmaciones de derechos.

17. Martínez DíEz, Gonzalo, Martínez DíEz, Emiliano, Martínez Llorente, Félix: Colección de documentos medievales de las villas guipuzcoanas (1370-1397), San Sebastián, Diputación Foral de Guipúzcoa, 1996, p. 187.

18. Idem: Colección de documentos medievales... (1200-1369)...op. cit., pp. 49-50.

19. Ibidem, p. 63.

20. Orella Unzue, José Luis: Op. cit., p. 3; Sobre la formación de Guipúzcoa como entidad políticoadministrativa véase BARRENA OSORO, Elena: La formación de Guipúzcoa. Transformaciones en la organización social de un territorio cantábrico durante la época altomedieval, San Sebastián, 1989, pp. 157-178.

21. Martínez DíEz, Gonzalo, Martínez DíEz, Emiliano, MARTínez Llorente, Félix: Colección de documentos medievales... (1200-1369)...op. cit., p. 46.

22. Ibidem, pp. 156-158, 188-190, 202-204. 
Aprovechando la indefinición jurisdiccional y territorial y la debilidad del todavía reciente fenómeno urbano, los Parientes Mayores y sus acólitos, particulares e incluso otras comunidades y concejos tratarán de fiscalizar los beneficios que reportaban las riquezas forestales; no olvidemos que, en muchos casos, son precisamente los Parientes Mayores, o linajes secundarios vinculados a ellos, los que controlan la industria ferrona. Como ya se ha mencionado, la propiedad de los montes recaía en el rey, quien hacía merced de ellos a los concejos, a través de las cartas-puebla. Pero las cartaspuebla adjudicaban a las villas territorios difusos, que permanecerán sin definir o poco definidos hasta que las villas se empeñen, entre mediados del siglo XIV y comienzos del XVI, en establecer y fijar claramente los límites entre unas entidades jurisdiccionales y otras (urbanas o particulares-señoriales), reafirmando así su propiedad sobre los mismos. Hasta que dicha definición se produzca, los mencionados grupos tratarán -y conseguirán- de usurpar gran cantidad de montes y bosques, desde finales del siglo XIII y durante los siglos XIV y $\mathrm{XV}^{23}$. Esta situación dará lugar a una importante conflictividad. La conflictividad tomó cuerpo en el siglo XIV; básicamente, tres fueron los modelos de conflictividad: conflictividad jurisdiccional -entre concejos-, conflictividad por confusión entre jurisdicciones señoriales y concejiles, y conflictividad entre ferrones y concejos. El que aquí interesa en estos momentos es el primer modelo ${ }^{24}$.

\section{CONFLICTIVIDAD Y ACUERDOS FRONTERIZOS}

Como se acaba de afirmar, los Parientes Mayores no son los únicos protagonistas de las usurpaciones; éstas serán realizadas también por otras villas y comunidades y por particulares. La primera Concordia entre diferentes comunidades, en Guipúzcoa, data de 1345, cuando el concejo de Deva se avino con los moradores de Marquina de Suso sobre límites y aprovechamientos en torno al monte Aranoguíbel ${ }^{25}$. A partir de este momento, van a ser muy numerosas las concordias alcanzadas -para evitar los costosos pleitos-, que racionalizan el uso y aprovechamiento de cada una de las partes en los montes y territorios limítrofes. Estas concordias darán lugar a la partición de montes - proceso que se prolonga entre los siglos XIV y XIX-, siendo aprovechados de forma individual por las diversas comunidades, o, por el contrario, a la creación de

23. DíAZ De DuranA, José Ramón: «Aproximación a las bases materiales del poder de los Parientes Mayores guipuzcoanos en el mundo rural: hombres, seles, molinos y patronatos», DíAZ DE DURANA, José Ramón (Ed.): La lucha de bandos en el País Vasco: de los Parientes Mayores a la Hidalguía Universal. Guipúzcoa, de los bandos a la Provincia (siglos XIV a XVI), Bilbao, pp. 258-259; LEMA Pueyo, José Angel, Fernández De Larrea, Jon Andoni, García Fernández, Ernesto, Munita LOINAZ, José Antonio, DíAZ DE DuRANA, José Ramón: Los señores de la guerra y de la tierra: nuevos textos para el estudio de los Parientes Mayores guipuzcoanos (1265-1548), Donostia, 2000, pp. 53-54.

24. Para las otras dos consultar ARAGÓn RUANO, Álvaro: «La importancia de los montes comunales en el desarrollo de la sociedad urbana vasca en el tránsito del medievo a la modernidad (siglos XV y XVI)», BRSBAP, LIX, 2003-1, pp. 76-81.

25. Martínez Díez, Gonzalo, Martínez Díez, Emiliano, Martínez Llorente, Félix: Colección de Documentos... (1200-1369)...op. cit., pp. 247-248. 
montes comunes, montes proindivisos, montes francos y parzonerías, donde algunos usos eran comunes. Por medio de las mencionadas concordias, la propiedad tanto en las parzonerías como en los montes comunes y proindivisos, y montes francos recae en los municipios, no en los vecinos y moradores, aunque el aprovechamiento sea comunal. En torno al siglo XIV, las villas introdujeron un concepto más moderno de propiedad convirtiéndola en móvil y divisible. Este concepto afectó también a las propiedades municipales, originando la disolución de los proindivisos y la demarcación de los términos municipales. Algo parecido ocurrió también en Vizcaya, donde hay al menos 50 proindivisos, que describe y enumera Arantza Gogeascoechea: destacan Marquina y Durango por ser las que más proindivisos poseen, seguidas de Busturia y Zornoza con una proporción del $75 \%$ de municipios que forman proindivisos, Arratia y Bedia y las Encartaciones en torno al $60 \%$, siendo Uribe la zona menos caracterizada por la presencia de proindivisos, ya que sólo el 28 '5 \% de los municipios participan de la fórmula ${ }^{26}$.

En Guipúzcoa son numerosos los acuerdos de deslinde y amojonamiento de montes y pastos durante los siglos XIV, XV y XVI. En 1397 se emitió sentencia en el pleito entre San Sebastián y Fuenterrabía, quienes se acusaban mutuamente de destruir, talar, quemar y vender porciones que eran comunes a ambos en Jaizquíbel, obligando a ambas villas a explotar el bosque de forma igualitaria y sin «mala fee» ${ }^{27}$. Hay que tener en cuenta que, aún en el siglo XVI, los límites de las villas no estaban bien definidos y que los mojones eran arrancados o movidos de lugar. Todavía en 1544, Rentería y Oyarzun proseguían con el conflicto iniciado en tiempos de Juan II y Enrique IV. A pesar de la Sentencia Arbitral concedida por los Reyes Católicos el 7 de abril de $1491^{28}$, por la que los términos comunes de la villa de Rentería y de la Tierra de Oyarzun se dividían en tres partes iguales, correspondiendo $2 / 3$ a Oyarzun y $1 / 3$ a Rentería, aunque el aprovechamiento seguía siendo común, los problemas continuaron. Debido a ello se concedió una Real Orden en 1505 y una Sobrecarta en $1516^{29}$, por la que la reina doña Juana separaba definitivamente la tercera parte de Rentería de las dos terceras partes de Oyarzun.

La fundación de villas vino seguida por la anexión o incorporación de diversas aldeas a entidades mayores, tratando de evitar o amortiguar las consecuencias de la denominada «inseguridad bajomedieval», lo que provocó un nuevo foco de conflictos, en torno a los territorios y montes limítrofes, que se extenderían hasta el siglo XVII. El proceso se inició ya a mediados del siglo XIV -lo cual, en nuestra opinión erróneamente, ha sido interpretado por algunos como un síntoma de la crisis bajomedieval

26. GogeAscoecheA, Arantza: «Los montes proindivisos en Vizcaya», Lurralde, 22 (1999), pp. 299-322.

27. CRespo Rico, Miguel Angel, CruZ Mundet, José Ramón: Colección documental del archivo municipal de Rentaría, Tomo I, Donostia, 1991, pp. 93-100.

28. Archivo Municipal de Rentería (A.M.R.), B, 1, 2 / 7.

29. A.M.R., B, 1, 2 / 12. 
provocada por la llegada y expansión de la Peste $\mathrm{Negra}^{30}$ - con el avecindamiento de particulares, como muestra el caso del concejo de Salvatierra de Iraurgui (Azpeitia), que en 1348 admitió como vecinos, con todas sus propiedades, para regirse por su carta-puebla a 87 hombres $^{31}$.

Posteriormente, serán los colectivos que pueblan una serie de aldeas los que se avecindarán e incorporarán a algunas villas «...por auer maiores fuerça e poder, seyendo todos vezinos, para seruiçio del dicho sennor rey e a onra e prouecho de si mismos...». Concretamente, en 1348 la villa de Tolosa y los moradores de Alquiza y Asteasu acordaron carta de vecindad ${ }^{32}$. En este caso, los avecindados pasaban a regirse por el fuero de la villa a la que se unían y a contribuir en los repartimientos de la misma, conservando los aprovechamientos anteriores de sus términos. El acuerdo de vecindad ajustado por Segura e Idiazábal en 1384 rezaba así: «Pero ponemos que todos nuestros bienes, asi montes e tierras como seles e aguas e prados e pastos e yeruas, que finque para nos libremente para fazer dellos lo que quisieremos sin parte del dicho conçeio, asi commo los avriamos antes que este dicho contrabto fuese otorgado... ${ }^{33}$. Como demuestran los casos de Baliarrain, Orendain e Icazteguieta con Amézqueta y Abalcisqueta en 1390, o de Salvatierra de Iraurgui (Azcoitia) con las colaciones de Cestona, Aizarna y Acoa en $1384^{34}$, generalmente, las divisiones repartían entre las comunidades el aprovechamiento del bosque y madera, pero respetaban en común el pasto de ganados. Las razones de la división son diferentes en cada caso, pero todos responden a una causalidad similar: falta de conservación, excesos, usurpaciones, daños, desigualdad en el acceso y reparto de usos, diferencias demográficas, importancia desigual de la industria siderúrgica, etc. En las comunidades el aprovechamiento de los montes responde a tres tipos de lógica:

- En algunas comunidades de montes la participación está en función de la fogueración. A este modelo responden las comunidades de montes de Berástegui $(2 / 3)$ y Elduayen (1/3) y los montes proindiviso de Oyarzun (2/3) y Rentería (1/3).

- En otros municipios, no existe esta correspondencia y el reparto se realiza al $50 \%$, como en Amasa y Villabona.

- Hay municipios que no siguen ninguno de los dos modelos anteriormente propuestos, y en los que las cuotas se fijan tras una serie de pleitos, aunque siguiendo una serie de criterios como puede ser la propia fogueración. Este es el caso de Hernani, San Sebastián y, más tarde, Urnieta en torno a los montes francos del Urumea.

30. Al respecto véase ARAGÓn RUANO, Álvaro: «La importancia de los montes comunales...op. cit., pp. 65-69.

31. Martínez DíEz, Gonzalo, Martínez DíEz, Emiliano, Martínez Llorente, Félix: Colección de documentos medievales... (1200-1369)...op. cit., pp. 254-255.

32. Ibidem, pp. 256-257.

33. Martínez DíEz, Gonzalo, Martínez DíEz, Emiliano, Martínez Llorente, Félix: Colección de documentos medievales... (1370-1397)...op. cit., pp. 233-234.

34. Ibidem, pp. 193-196, 234-236 y 309-310. 
Las cuotas que se reparten suelen corresponder a la venta de madera, pero también al arrendamiento de los derechos de pasturaje ${ }^{35}$.

El conflicto entre las aldeas y sus villas se prolongó más de tres siglos, por lo que algunos límites, parzonerías, montes comunes y montes proindiviso no se acabaron de establecer hasta los siglos XVII y XVIII. Es de gran interés el caso de Amasa que había sido avecindada junto a Irura por Tolosa en $1385^{36}$, manteniendo «...sus terminos, pastos, aguas, e eruados e montes e seles e todas las otras sus heredades syn enbargo e mala voz del dicho conçeio de Tolosa nin de su voz.». En 1435, a causa del pago de repartimientos, las aldeas de Berástegui, Elduayen, Belaunza, Leaburu, Gaztelu, Lizarza, Oreja, Amasa, Irura, Anoeta, Hernialde, Cizúrquil, Aduna y Alquiza se opusieron a Tolosa, exigiendo la vuelta a su independencia jurisdiccional inicial. Ambas partes llegaron a un acuerdo a través de una escritura de composiciones, por la que las aldeas admitían su obligación de contribuir en los pechos establecidos por Tolosa, aunque éstos debían aprobarse con la presencia de los jurados de las vecindades.

Durante el siglo XVI las quejas de Amasa y otras aldeas de Tolosa continuaron. En 1553 Amasa, Lizarza y otras aldeas se quejaron de que Tolosa les había hecho pagar por segunda vez la foguera provincial. Ante la noticia de que, por las grandes necesidades del rey, éste había dado orden para que se pudiesen dividir las jurisdicciones de las villas, es decir, que las aldeas se pudiesen convertir en villas con separación de término y jurisdicción por una suma de dinero, las Juntas Generales de Ordicia de 1565 mandaron dar capítulo de que en caso de que alguna aldea pidiese la exención se le negara en nombre de la Provincia -en estos momentos Irún y Legazpia ya la demandaban-. En 1575 Cizúrquil, Albistur, Berástegui, Andoain, Amasa y demás consortes fueron agraviados por la Juntas, que dispusieron que los escribanos del número no hiciesen escrituras ni autos judiciales fuera de Tolosa. En las Juntas Generales de Guetaria de 1598 se votó sobre si la Provincia debía acudir a los pleitos a favor de las villas y costearlos; venció la postura favorable a que la Provincia fuese parte, pero sin costear los gastos. En 1600 se establecieron pleitos entre las villas y sus aldeas, por negarse éstas a ir a las cabezas de jurisdicción a las honras reales, alzamiento de pendón y alardes; las villas pidieron a la Provincia que siguiese estos pleitos en su favor.

35. Gogeascoechea, Arantza: Op. cit., p. 312; Lema Pueyo, José Angel, Fernández De Larrea, Jon Andoni, García Fernández, Ernesto, Munita Loinaz, José Antonio, Díaz De Durana, José Ramón: Los señores de la guerra...op. cit., pp. 229-232: «...que por la pastura de las dichas yerbas e ganados e montes d'esta carta en adelante para de cada anno de Sant Martin de nobienbre primero que viene sieteçientos maravedis de moneda vieja castellana ...que paguen por cada anno los dichos de Beraztegui a los dichos d'Elduayen para cada anno dozientos e treinta e tres maravedis e terçia de la dicha moneda... Otrosi, lo que Dios no quiera, el dicho busto e acto de bacas se obiese a desfazer e derramar en alguna manera...que los dichos de Beraztegui e Elduayen puedan arrendar e arrenden sus pastos, agoas e bados a quien e quales quisieren e por preçio e quantia o quantias que se abenieren para los tienpos que se abenieren e que el dicho (preçio) e contia sean las dos partes para los dichos de Beraztegui e la terçera parte para los d'Elduayen.».

36. Martínez Díez, Gonzalo, Martínez Díez, Emiliano, Martínez Llorente, Félix: Colección de Documentos Medievales... (1370-1397)...op. cit., pp. 242-243. 
En el trasfondo del enfrentamiento entre las villas y sus aldeas estaba la gran desigualdad participativa en el poder, derivada del procedimiento de regulación de votos de tipo fogueral. Durante todo el siglo XVI hubo repetidos intentos para cambiar el voto fogueral por el voto personal, y el sistema de tandas de la Audiencia del Corregidor, aunque finalmente no se consiguió. Esta problemática se trasladó al siglo XVII y se convirtió en un movimiento de exenciones, que comenzó al convertirse el Valle de Legazpia en entidad privilegiada dotada de mero y mixto imperio y separarse de la jurisdicción de Segura en 1609. Este acontecimiento sirvió de acicate a las aldeas pertenecientes a las jurisdicciones de Tolosa, Segura, Ordicia y Vergara. Pero estos cambios no se hubiesen producido de no contar con el apoyo del monarca, interesado en llenar sus maltrechas arcas, y de la mayoría de la Provincia.

La pésima situación por la que atravesaba la Hacienda Real castellana, tras la quiebra de 1607, favoreció la tramitación de las demandas de exención jurisdiccional directamente a través del Consejo de Hacienda. El triunfo de las aspiraciones de las aldeas de Tolosa, Segura y Ordicia se produjo así mismo por el apoyo de la mayoría de las entidades que integraban la corporación provincial, encabezadas por San Sebastián, Azpeitia y Azcoitia, quienes pretendían reorganizar en su favor la estructura y participación en el gobierno provincial. Finalmente, a las Juntas Generales de Elgóibar, celebradas en mayo de 1615, acudió Hernando Suárez, dando posesión de jurisdicción a las aldeas: Cegama, Berástegui, Andoain, Ataun, Idiazábal, Amézqueta, Albistur, Abalcisqueta, Amasa, Beasain, Orendain, Zaldivia, Ormaíztegui, Cizúrquil, Astigarreta, Mutiloa, Cerain, Icazteguieta, Ichasondo, Alcega, Alzo, Elduayen, Legorreta y Gainza. A cambio de la exención, cada nueva villa debía pagar 25 ducados por cada vecino. Los representantes de las nuevas villas debían visitar sus términos y amojonarlos con vara de justicia, y luego elegir alcalde ordinario, teniente y demás oficios, así mismo debían recibir de las villas a las que habían pertenecido todos los pleitos, papeles y padrones referentes a sus lugares, pudiendo ejercer justicia.

La Provincia de Guipúzcoa, a través de un memorial, justificó las exenciones:

1. En esos lugares estaban los solares y casas de los hidalgos primeros pobladores de la provincia, que poblaron las villas.

2. Los lugares se sometieron por su voluntad a las villas, desde hace 300 años, por defenderse de los bandos de los Parientes Mayores. En dicha sumisión hicieron capitulaciones y condiciones, reservando para sí sus parroquias, términos, propios, regidores, fieles y síndicos.

3. Con el paso del tiempo, las tres villas comenzaron a vejarles y molestarles tratándoles con desigualdad, sin guardar las condiciones con las que se sometieron, surgiendo un perpetuo litigio.

4. Aunque en muchas ocasiones intentaron eximirse no lo consiguieron. Lo consiguieron finalmente por Cédula Real, para mayor paz y quietud.

7. A las nuevas villas se les dio posesión de jurisdicción ordinaria.

11. En las Juntas de Deva de diciembre de 1615 se admitieron finalmente las exenciones. 
Amasa pagó 1.331.250 maravedís para obtener la exención, cifra que costearon sus 132 vecinos tomando el dinero a censo. Muchas de las nuevas aldeas procedieron a la venta de terrenos concejiles baldíos a particulares, a fin de costear los gastos generados por el pago de la exención. Andoain procedió a censar sus bienes propios y rentas, a imponer sisa sobre los mantenimientos y a vender 33.511 pies de manzanos de monte concejil, y en Cizúrquil se impusieron varios censos a sus 40 caserías y se vendieron 42 porciones de monte compradas por 33 personas $^{37}$.

\section{LA EXPANSIÓN DEMOGRÁFICA Y LA AMPLIACIÓN DEL ESPACIO OCUPADO}

Como ya se mencionaba, fruto de la indefinición territorial, pero al mismo tiempo del crecimiento demográfico y económico que experimentó Guipúzcoa entre los siglos XII y XV, que generaron nuevas necesidades y el intento por parte de algunas colectividades y particulares de usurpar ciertas áreas forestales para abastecer su desbordante demanda, surgieron largos, interminables y costosos pleitos que supusieron una importante rémora para el desarrollo de muchas villas. El indiscutible crecimiento que experimentaron la demografía y la economía guipuzcoanas, desde finales del siglo $\mathrm{XIV}$, pero sobre todo desde mediados del siglo XV, ampliaron el asedio y la disputa por los recursos forestales, acelerando los problemas de deforestación.

Eran muchas las actividades interesadas en la explotación de los montes y bosques: industria siderúrgica y armamentística, industria naval, construcción de edificios, industria de la sal, industria textil, usos domésticos, etc. Debido a que cada vez su número era mayor y mayor también su voracidad, y a que ya se empezaban a manifestar los primeros síntomas de retroceso forestal, las villas que, como ya hemos dicho, habían sufrido contínuas usurpaciones por parte de particulares y otras entidades municipales, se vieron en la obligación de recuperar y blindar la propiedad de sus montes, previa definición de sus territorios. La formación de las comunidades de montes ha de ser vista, precisamente, como la consecuencia del proceso de territorialización al que se verán obligados muchos municipios, para poder disfrutar plenamente de sus montes.

Los montes y bosques van a ser instrumentos estratégicos para los municipios, en un momento de expansión. Por un lado, los montes se van a convertir en la principal fuente de recursos, a través de la venta de leña y madera, o del arriendo de pastos, para hacer frente tanto a gastos ordinarios como extraordinarios. Por otro lado, los terrenos ocupados por el bosque servirán para el asentamiento de nuevos colonos y caserías, asegurando la expansión demográfica, la creación de nuevos pastos y prados para el

37. ARAGÓn RuANO, Álvaro: «Amasa-Villabona en la Edad Moderna», Historia de Amasa-Villabona, 2003, pp. 175-214; TRUCHUELO, Susana: La representación de las corporaciones locales guipuzcoanas en el entramado político provincial (siglos XVI-XVII), Donostia, 1997, pp. 183-232; AYERBE IRIBAR, María Rosa: «Andoain, de tierra a villazgo (1379-1615). Un caso modélico de preautonomía municipal en Gipuzkoa», Leyçaur, nº 0 (1996); Archivo Municipal de Fuenterrabía (A.M.F.), E, 2, I, 10; Archivo General de Guipúzcoa (A.G.G.-G.A.O.), JD IM 1/12/18; A.G.G.-G.A.O., JD IM 1/18/14 y 16. 
desarrollo y expansión de la ganadería, y fuente de abastecimiento para la fabricación de carbón vegetal, materia prima imprescindible para las insaciables ferrerías, y para la obtención de materiales para la construcción naval y la construcción de edificios.

En el caso concreto de la expansión demográfica contamos con innumerables testimonios. Para mediados del siglo XV, comienzan a ocuparse las zonas más alejadas del núcleo urbano, donde se situaba la representación del poder religioso y político, cuya manifestación más visible era el edificio de la iglesia parroquial y la casa concejil. El avance demográfico durante la Baja Edad Media había provocado la ocupación de la práctica totalidad de las tierras bajas y de aluvión, más ricas y aconsejables para el desarrollo de una agricultura tecnológicamente pobre, como era la que se desarrollaba en la época en territorio guipuzcoano, por lo que no es casualidad que la mayor parte de los montes concejiles se sitúe en las partes más altas de la jurisdicción, mientras que las partes más bajas son de propiedad particular. Por ello, muchos se vieron obligados a colonizar zonas vírgenes e inhóspitas en puntos geográficos marginales situados a mayor altura. En el caso de Oyarzun se menciona que antes de la sentencia arbitral de 1491 existían 30 casas en la frontera con Rentería, número que se amplió a 70 para 1508. Muchas de estas casas se situaban en la propia zona fronteriza con Rentería, en intrincados vallecitos, donde la práctica agrícola no era fácil, en torno a pequeñas colinas, nunca superiores a los 200 metros de altura o en pequeñas vegas formadas por los afluentes del río Oyarzun, que hoy día podemos localizar en los barrios de Iturrioz y Ugaldecho ${ }^{38}$.

En Zumárraga, su concejo vendió varias porciones de tierra del ejido concejil el día 25 de julio de 1537, «...por pagar las debdas que el dicho concejo en seguimiento de los pleitos que ha tratado e trata con don Felipe de Lazcano sobre el preuilegio e patronazgo de la dicha iglesia parroquial de Santa Maria e con el concejo e vecinos de Villarreal sobre el puente de Cufiaurchipi y en razon de la paga y entrega de ellos...». El concejo de Zumárraga obtuvo ingresos por 330 ducados y 125 maravedís de manos de 21 particulares, a los que se concedieron terrenos del ejido concejil pegantes a sus posesiones particulares; terrenos cuya extensión variaba entre 1/2 y 8 huertas, siendo cada huerta de 3 estados de ancho por 70 de largo, lo que significa que cada huerta supondría unos $790 \mathrm{~m}^{2}$, algo menos de un área de terreno. Por tanto, el concejo de Zumárraga enajenó en 1537 unas 80 hectáreas (100 huertas) de terreno del ejido concejil; la mayoría terrenos cultivables y una sola tierra castañal, robledal y heredad.

De los topónimos que se citan en las escrituras de venta sólo una pequeña parte ha podido ser localizada; estos topónimos se sitúan en su mayoría en la falda del monte Izazpi, en el ejido de Olarte, en torno a la ermita de la Antigua de Zumárraga, en los terrenos que limitan con Ezquio-Ichaso y Azpeitia (Oratecoeguia, Helorriaga, Soraizbizkar, Cortazabal, Belçaloyaga, Sorachipi, Muntolaza, Cerro de Leturia, Albiçamendia), generalmente en la zona de media ladera, pero a veces buscando las

38. Véase ARAgón RuAno, Álvaro: La casa «Torrea» de Iturriotz. Historia y Patrimonio cultural, Oiartzun, 2003, pp. 169-170. 
zonas más llanas y cercanas al rio Urola, como demuestra el caso de la venta de una tierra castañal, robledal y heredad a Juan de Echeuerria, el de Liçeraçu, junto a su heredad y al «...rio publico e real que desciende del Valle de Legazpia para Azcoitia a teniente a la presa de nuestros molinos (concejiles) e de Juan de Sasieta e por partes de arriba a por limites el camino publico e real que ba e pasa por la otra ladera a nuestro egido conçegill...», lo cual es lógico si tenemos en cuenta que ya para entonces se había producido la bajada de la población desde el entorno de la iglesia de la Antigua a la llanura del Urola y la ocupación de las riberas y tierras de Eizaga, donde se ubica actualmente el núcleo urbano ${ }^{39}$. Como en el caso de Oyarzun, parece que aquí también la expansión se fue realizando en anillos concéntricos, en un movimiento centrífugo, desde el núcleo urbano hacia los límites con otras localidades.

Este mismo fenómeno expansivo, obligó a los concejos de las respectivas demarcaciones municipales, por un lado, a delimitar sus propios territorios, y, por otro, a buscar acuerdos con las poblaciones circunvecinas para poder disfrutar de sus territorios más inaccesibles y no verse lesionados por las usurpaciones de otros, pero al mismo tiempo para tener derechos de uso y aprovechamiento que, en principio, no les correspondían y pertenecían a sus vecinos, con lo que pudieron dar cabida a un número cada vez mayor de vecinos y moradores; fórmula sin la cual, no lo hubiesen podido llevar a efecto, ante la exigüidad de montes concejiles con los que contaban algunos lugares. Por supuesto, el concepto de exigüidad o cortedad de medios es relativo y proporcional al potencial demográfico e industrial de cada una de las villas y lugares guipuzcoanos; potencial que también puede tener variaciones cronológicas, no sólo geográficas.

\section{LA FORMACIÓN DE COMUNIDADES DE MONTES}

Para evitar los costos derivados de los continuos pleitos, en la mayoría de los casos se acabó optando por la firma de concordias y convenios, que dieron lugar a la formación y creación de montes francos, montes comunes y proindivisos, y parzonerías. La firma de concordias vino a solucionar algunos de los problemas anteriormente descritos y se convirtieron en la referencia y la base legal ante futuros conflictos -que no desaparecieron-, puesto que las partes siempre echarán mano de ellas en sus alegaciones. En este apartado, trataremos de analizar cada una de las fórmulas enunciadas.

\subsection{Montes comunes y proindivisos, y montes francos}

Eran numerosos los montes disfrutados proindiviso por los lugares de Guipúzcoa, a través de concordias de pastos, prácticamente todos aquellos lugares que poseían montes colindantes con otros lugares. He aquí algunos ejemplos que surgieron en la época que nos ocupa: Zumaya-Deva (1391), Azcoitia-Azpeitia (1458), OyarzunRentería (1491) y Régil-Vidania-Goyaz-Albistur $(1545)^{40}$. En la gran mayoría de los casos, tras largos pleitos, se establecía el disfrute común de los montes proindivisos y

39. Archivo Histórico de Protocolos de Gipuzkoa (A.H.P.G.), 1 / 3949, fols. $1 \mathrm{r}^{\mathrm{o}}-39 \mathrm{v}^{\mathrm{o}}$. 40. Ibidem, p. 51. 
se repartía el producto de montes, en función de la participación de cada villa o lugar en dichos montes. A pesar de ello, cada villa mantenía la propiedad y jurisdicción sobre su parte. El punto de reunión solía ser alguna ermita o casería situados en la frontera de las entidades, aunque no tenían una continuidad o regularidad en el tiempo, sino que se convocaban en función de las necesidades. Dos casos concretos, el de los montes comunes y proindivisos de Oyarzun y Rentería y el de los montes francos del Urumea, nos servirá de ejemplo.

Los conflictos entre el Valle de Oyarzun y Rentería se remontan a la propia fundación de la villa de Villanueva de Oyarzun, con fuero de San Sebastián, en el barrio de Orereta del mencionado valle en 1320. Los conflictos en torno a los montes limítrofes surgieron, entre otras cuestiones, debido a que en la carta-puebla de Rentería o Villanueva de Oyarzun se le adjudicaron a la nueva entidad los montes y territorios que correspondían a la anterior, esto es, al llamado Concejo de Oyarzun: «E otrosi les mandamos e otorgamos que ayan sus montes e sus pastos e sus terminos e puertos e fuentes e seles e las franquezas e las libertades que an por preuillegios e por cartas e en otra manera que lo ayan todo bien e conplidamente, asi como los han e los ouieron en tienpo de los otros reyes onde nos venimos e en el nuestro fasta aqui quando se llamauan conceio de Oyarço». Los fueros de este antiguo Concejo de Oyarzun, con autoridades y alfoz propios, habían sido concedidos por Alfonso VIII en una fecha que se desconoce -aunque probablemente muy próxima a la concesión hecha por el mismo monarca a Fuenterrabía en 1203, y nunca posterior a 1214-, siendo confirmados por Fernando III en 1237: «...illos terminos, montes defesas et pascua, que uobis prenominatus rez, auus meus, concessit et in uita sua et usque as iobitum eius tenuistis, ut ea iure hereditario habeatis et possideatis pacifice et quiete... ${ }^{41}$.

Pero en el año 1453 el Valle de Oyarzun obtuvo su carta-puebla ${ }^{42}$ y a partir de ahí surgió una importante pugna tanto por la representatividad en las Juntas Generales de Guipúzcoa -resuelta en 1509-, todavía en manos de Rentería, como por el uso y disfrute de los montes limítrofes. De todas formas, en ninguno de los casos se especificaban

41. Martínez DíEZ, Gonzalo, Martínez DíEz, Emiliano, MartínEZ Llorente, Félix: Colección de Documentos Medievales... (1200-1369)...op. cit., pp. 142-144. Conviene recordar las palabras de José Antonio Munita Loinaz: «En lo referente a los límites territoriales originalmente otorgados al concejo de Oyarzun, la problemática se oscurece aún más a falta de testimonios paralelos y sólo podemos mantener como razonable hipótesis que se tratara de la cuenca natural formada por el río Oyarzun, desde su nacimiento en la frontera navarra hasta la desembocadura del mismo curso fluvial, lo que en 1328, fundada ya «Villanueva de Oiarzo», todavía se conocía como el «puerto de Oyarçun» distinguiéndolo del «Pasaje»... si identificamos «Belfa» con el castillo de Beloaga, hipótesis verosimil aunque no definitiva, estaríamos haciendo pasar el límite meridional de Fuenterrabia por la divisoria natural de aguas entre el Bidasoa y el río Oyarzun, lo que significa a su vez que en 1203 Alfonso VIII respetó la demarcación del dicho valle, no adjudicándolo a Fuenterrabía.» (MUNITA LOINAZ, José Antonio: «El original más antiguo del Archivo Municipal de Rentaría: el privilegio rodado de Fernando III al concejo de Oyarzun (20.marzo.1237)», Bilduma, 2 (1998), pp. 94 y 98).

42. Tena García, María Soledad: La sociedad urbana en la Guipúzcoa costera medieval: San Sebastián, Rentería y Fuenterrabía (1200-1500), Donostia, 1997, p. 269. 
los límites; de hecho el primer amojonamiento de Rentería y Oyarzun data de 1495. El 7 de abril de 1491 en Sevilla los Reyes Católicos concedieron una sentencia arbitral, por la cual los montes limítrofes entre ambas se dividían en tres partes, correspondiendo la propiedad de dos de ellas al concejo de Oyarzun y una al concejo de Rentería. Sin embargo, el uso y aprovechamiento seguía siendo común, tanto para el corte de leña y madera como para el pasto del ganado. Cuando una de las partes quisiese hacer venta o enajenación, debía ser de común acuerdo con la otra. El 28 de febrero de 1495, y en virtud de la mencionada sentencia de 1491, se procedió a la división y partición de los términos jurisdiccionales entre Rentería y Oyarzun. Finalmente, el 11 de julio de 1495 se llevó a cabo el amojonamiento de los términos colindantes y la toma de posesión por el concejo de Rentería del territorio asignado a ella ${ }^{43}$.

Pero tras esta sentencia los problemas, desavenencias e incluso muertes continuaron. Esta situación debe ser encuadrada en las consecuencias de la expansión demográfica, que se venía produciendo en el entorno guipuzcoano desde mediados del siglo $\mathrm{XV}$ : en los 17 años que median desde la concesión de la sentencia de 1491 hasta la sentencia concedida en 1508 por el Consejo Real, en el barrio de Iturrioz (Oyarzun contaba con otros dos, Elizalde y Alcíbar) se habían construído otras 40 casas. Es decir, antes de 1491 existían en la zona 30 casas, pero en 1508 ya eran 70, lo cual provocó, en palabras de los testigos, que las dos partes concedidas entonces a Oyarzun se esquilmaran rápidamente. Para solucionar esta situación, en 1505 doña Juana concedía una Real Provisión por la que separaba definitivamente el aprovechamiento de leñas y madera de la tercera parte para Rentería de las dos terceras partes correspondientes a Oyarzun, cuyos habitantes «...no puedan cortar ni se aprouechar d'ellos syn licencia e consentimiento de la dicha villa de la Renteria...», aunque el aprovechamiento del pasto para el ganado seguía siendo común: «...quedando por comun todos los terminos de la dicha villa de la Renteria e de la dicha tierra de Oyarun para todos los ganados de los vezinos de la dicha villa e de la tierra de Oyarun solamente para el pasto comun e no para mas...». Oyarzun envía un alegato diciendo que se siente agraviada, pues la tercera parte adjudicada a Rentería es más amplia y poblada de bosques, lo que perjudica a las caserías y ferrerías situadas en el límite con Rentería; de no remediarse esta situación se produciría la despoblación de la mencionada área. Concretamente, la tierra de Oyarzun pretendía que las 70 casas situadas en la frontera con Rentería pudiesen usar de la suegurra o leña para cocinas y usos domésticos que se extraía de los cercanos montes de Rentería.

Una sentencia del Consejo Real fechada en 11 de abril de 1508 concede a las 70 casas de las frontera con Rentería el derecho a "...solamente cortar e sacar leña acuestas para los fuegos de sus casas e non de otra manera ni para otro aprouechamiento alguno de los montes...». A esta sentencia responde Oyarzun pidiendo que, si no para cortar y vender la leña, sí se deje la comunidad de montes para sacar la leña para sus casas en acémilas, puesto que aunque los mojones están cercanos a las casas, no así la

43. ARENZANA, Txema: «Errenteria a través de sus mugas», Bilduma, 15 (2001), pp. 14 y 118. 
leña, por los seles y heredades particulares que había en medio. En sentencia de revista y en Real Ejecutoria del 7 de agosto de 1508 se añade a la primera sentencia que puedan transportar leña a cuestas o en acémilas en la cantidad requerida, a condición de que no hagan carbón ni corten ni saquen más de lo que necesiten ${ }^{44}$. Los conflictos entre Oyarzun y Rentería, en torno al derecho de suegurra continuarán durante todo el siglo XVI -e incluso se volverán a reproducir durante el siglo XVIII-. En 1574 y 1591, reunidas ambas partes en el habitual punto del caserío Arizmendi, ante la indefinición de los límites -debido a que los mojones se movían de lugar-, y los problemas que de ello se derivaban, se estableció una concordia de pastos y se llevó a cabo un rol de las 70 casas que debían y podían disfrutar de la leña para uso doméstico, respectivamente ${ }^{45}$.

Los montes francos del Urumea también eran montes comunes y disfrutados proindiviso. Como su propio nombre indica hubo un tiempo en que era francos, esto es, el disfrute de sus recursos era franco, libre, gratuito y prácticamente ilimitado; pero esto acabó cambiando. Su constitución data del 2 de agosto de 1379, cuando Hernani y San Sebastián, de común acuerdo establecen que «abemos fecho e facemos vezindade vnidad en vno...». Por dicho convenio se regula que cada una de las partes conserve $y$ "...finquen en salbo todos los terminos, montes e heredat segund los han e tienen mojonados...», se establece la comunidad de pastos, siendo el pasto libre de día y de noche, así mismo se permite el libre corte de madera, pero bajo la condición de que se aproveche en San Sebastián y Hernani, se protegen los árboles llamados cruzados, adecuados para la construcción naval, y se prohibe su corte para la fabricación de carbón ${ }^{46}$.

En 1411 la Catedral de Pamplona firmó una concordia con San Sebastián y Hernani sobre la propiedad de los 22 seles que tenía en dichos montes, concediendo el usufructo de los mismos a las mencionadas villas. Coincidiendo con el proceso de expansión demográfica del siglo XV y, con él, el de la industria siderúrgica, la explotación y la disputa en torno a los recursos forestales irán en aumento. Ello produjo el enfrentamiento entre los intereses de los mencionados concejos y los dueños de ferrerías del Urumea. Para acabar con las diferencias suscitadas, el 8 de mayo de 1461 se reunieron representantes de las villas, las cofradías de mareantes de Santa Catalina y la de San Nicolás, y los dueños de ferrerías que, entre otras cosas, fijaron la correspondencia entre las villas, a razón de 6 para San Sebastián y 4 para Hernani. En 1516 los 22 seles de la Catedral de Pamplona fueron cedidos, en régimen de censo enfiteútico, a cambio de un canon anual, quedando la jurisdicción y propiedad de los seles proindiviso y sus productos repartidos en la mencionada proporción de 6 y 4 . En 1534 Urnieta comienza a reclamar su participación en los aprovechamientos del Urumea, y tras una serie de inestables acuerdos con Hernani y San Sebastián, finalmente en 1671 se llega

44. A.M.R., B, 1, 2 / 12.

45. A.M.R., C, 5, II, 5 / 4.

46. Martínez Díez, Gonzalo, Martínez Díez, Emiliano, Martínez Llorente, Félix: Colección de Documentos Medievales... (1370-1397)...op. cit., pp. 103-106. 
a la definitiva división de los Montes Francos del Urumea, quedando divididos los montes en 9 partes, 4 para San Sebastián, 3 para Hernani y 2 para Urnieta ${ }^{47}$. Las partes se reunían anualmente en el paraje de Oriamendi (más tarde escenario de la famosa batalla, durante la Primera Guerra Carlista), para ocuparse de la gestión conjunta de los montes, llevar la contabilidad, dar licencias de corte y repartir el producto de montes en la ya mencionada proporción, ya en 1683 y $1695^{48}$.

Existen además una serie de ejemplos especiales en los cuales los miembros de las parzonerías o comunidades no son entidades municipales, sino particulares o entidades más pequeñas, caso de la Comunidad de los montes «learberros», en Sorabilla, los montes de las anteiglesias de Udala y Garagarza, y los «montes de hidalgos», disfrutados por hacendados y, posteriormente, por no hacendados, en Mondragón. En casos excepcionales, los concejos podían firmar convenios con algunos particulares de otras jurisdicciones vecinas, que tenían sus viviendas y bienes cercanos a sus montes, para que tuviesen los mismos derechos de pasto y aprovechamiento que el resto de habitantes de la villa. Así ocurría en los montes de Otabarza en Zumaya, donde tras la concordia firmada el 16 de septiembre de 1427, se reconocía a ciertos moradores de Sayaz los mismos derechos que a los vecinos de Zumaya, en el pasto del ganado, aprovechamiento de bellota y madera ${ }^{49}$. En cuanto a las Comunidades de vecinos, caso de la de Zubieta, los montes comunales eran tratados como montes de la jurisdicción de la Comunidad, mientras que las heredades de una casa, parcelas agrícolas, castañales o manzanales, se consideraban jurisdicción de la misma ${ }^{50}$.

\subsection{Parzonerias y Uniones}

Dos son los ejemplos que aquí se van a analizar: el de la Unión o Mancomunidad de Aralar y Enirio y el de la Parzonería General de Guipúzcoa y Álava, que englobaban a entidades de dos provincias diferentes. El origen de la Mancomunidad de pastos en la Unión de Enirio y Aralar es muy antiguo. La primera concordia se celebró en 1390, siendo reformada en 1411 y 1534, entre Amézqueta y Abalcisqueta con Orendain, Baliarrain e Icazteguieta, por la que se establecía el libre pasto de sol a sol ${ }^{51}$. En 1400 Enrique II donó a su vasallo Juan de Amézqueta, en juro de heredad, los montes de Aralar y Enirio. Ello provocó importantes conflictos con las colaciones señaladas, por lo que en 1409 Juan de Amézqueta -como ya hizo Fernán Pérez de Ayala unos años antes en el otro caso que describiremos- procedió a la venta de «la sierra de Aralar y los montes e devisas de Enhirio», por 1.400 florines de oro del cuño de Aragón,

47. BANUS Y AgUiRRE, José Luis: «El límite meridional de San Sebastián. La villa de Hernani y los montes francos de la Urumea», BRSBAP, 1971, pp. 50-58.

48. Archivo Municipal de Hernani, C, 5, II, 2.

49. ARAGÓn RuANO, Álvaro: El bosque guipuzcoano...op. cit., pp. 50-52.

50. GonZÁLEZ Dios, Estíbaliz: «Las «comunidades de vecinos» de la jurisdicción de San Sebastián, de su organización en la época moderna a su persistencia en la contemporánea. El caso de la comunidad de Zubieta», Boletín de Estudios Históricos de San Sebastián, 38 (2004), p. 680.

51. Archivo Municipal de Villafranca de Ordicia (A.M.Or.), Unión de Aralar y Enirio, Lib. 1, exp. 1. 
la mitad a la villa de Villafranca y sus vecindades -Legorreta, Ichasondo, Arama, Alzaga, Gainza, Zaldivia, Ataun, Beasain y Lazcano- y la otra mitad a Amézqueta, Abalcisqueta, Orendain, Baliarrain e Icazteguieta ${ }^{52}$. Por tanto en la fecha señalada quedaba constituída la Unión o Mancomunidad de Aralar y Enirio, integrada por los pueblos que conforman las dos Uniones de Bozue: Bozue Mayor, llamada luego Unión de Amézqueta, y Bozue Menor, llamada después Unión de Villafranca. El patrimonio de la Comunidad se dividía en dos partes iguales, una para la Unión de Bozue Mayor y otra para la de Bozue Menor, mitad que era dividida en partes iguales entre los miembros de cada una de ellas, es decir, cinco partes iguales en el primer caso y diez partes iguales en el segundo. La Junta General se celebraba en la casería de Suegui, en Abalcisqueta, integrada por los alcaldes de cada uno de los quince municipios.

Pero la constitución de la Unión en 1409, no acabó con los problemas, puesto que, para consolidar su territorialidad, algunas entidades locales debían resolver ciertos flecos con diferentes propietarios particulares, tanto laicos como eclesiáticos. En 1432 una sentencia arbitral vino a resolver los pleitos que Villafranca, Amézqueta y Abalcisqueta mantenían con Ojer de Amézqueta, señor de Lazcano, quien había adquirido ciertos seles de la casa Loyola en Aralar, ya que el reparto realizado en 1409 no había satisfecho a la primera; la sentencia provocó la venta de los seles por Juan López de Amézqueta a Villafranca y sus vecindades por 10.000 maravedís $^{53}$. Por su parte, los conflictos del monasterio de Santa María la Real de Roncesvalles, que tenía en propiedad varios seles en Aralar, con la recién creada Mancomunidad serán habituales hasta que en 1452 una sentencia arbitral reconoció la posesión y amojonamiento de los mismos $^{54}$. Durante el siglo XVI esos seles serán disfrutados por Villafranca en régimen de censo enfiteútico. El impago continuado del mencionado censo llevó finalmente al monasterio a vender los seles a Amézqueta en 1717, que desde ese momento tuvo que enfrentarse a Villafranca y Lazcano por su disfrute ${ }^{55}$.

Por otra parte, Lazcano, que en un primer momento se había quedado fuera de las concordias, reclamó el uso y aprovechamiento de los montes de Aralar y Enirio. Una sentencia arbitral en 1479 le reconoció ese derecho, pero la jurisdicción civil y criminal seguía en manos de Villafranca. Durante el siglo XVI tuvo que enfrentarse a Amézqueta y Abalcisqueta por el libre pasto de sus vecinos en Aralar, derecho que acabó obteniendo por sentencias del Corregidor y la Real Chancillería ${ }^{56}$. Por último, los conflictos surgidos con la vecina Navarra se resolvieron con la firma de una concordia suscrita por la Provincia de Guipúzcoa y el Reino de Navarra en 1519, confirmada en 1525 y sobrecarteada en $1526^{57}$.

52. A.M.Or., Unión de Aralar y Enirio, Lib. 1, exp. 2.

53. A.M.Or., Unión de Aralar y Enirio, Lib. 1, exp. 4.

54. A.M.Or., Unión de Aralar y Enirio, Lib. 1, exp. 5.

55. Ayerbe IrIBAR, María Rosa: «La Unión o Mancomunidad...op. cit., p. 16-19.

56. A.M.Or., Unión de Aralar y Enirio, Lib. 2, exp. 2.

57. A.G.G.-G.A.O., JD IM 2/18/11. 
Por su parte, la Parzonería de Guipúzcoa y Álava se formó tras la firma de una concordia en la cueva de San Adrián el 16 de noviembre de 1430, previa compra en 1401 de Segura a Fernán Pérez de Ayala, que había recibido los montes en donación de manos del rey: «...Y luego ambas las dichas partes, de un acuerdo y conformidad, dijeron que por cuanto entre las dichas partes habia dudas de tiempo a esta parte sobre los términos y pastos, prestaciones y fruto e uso de los montes y términos que son en Alzania, y por quitar las dichas questiones y debates y pleitos que entre las dichas partes podian de ello nacer que otorgaban y otorgaron por si y en nombre de los dichos concejos e lugares cuyos oficiales y partes eran que las dichas partes e cada una de ellas tenían de haber e ovieren de aqui adelante para siempre jamás por comuneros e comunmente usasen, paciesen y cortasen los montes, yerbas y pastos y vebiesen las aguas, e comiesen lande, etuviesen toda otra prestacion de los dichos montes y terminos... $\|^{58}$. El uso y aprovechamiento común de los recursos de estos montes se extendía tanto a vecinos como a moradores, que podían tener en ellos su ganado permanentemente, de día y de noche. Aunque la propiedad recae en los concejos parzoneros, la posesión está en manos de los vecinos. Los recursos que se pueden aprovechar cubren un amplio abanico: pastos, hierbas, aguas, leña, madera, hoja, etc. Pero son los recursos relacionados con la ganadería los más importantes. La concordia establece ya las primeras fórmulas de gestión, puesto que surge como consecuencia de una reunión de las partes, y crea un cuerpo de examinadores, encargados de evaluar los recursos existentes cada año, para decidir la cantidad de cabezas de ganado que se podían echar al monte. Esta distribución se aplicaba básicamente al ganado porcino, cuya importancia para estas fechas era alta. La distribución del pasto (hayucos y bellotas) se hacía a partes iguales entre alaveses y guipuzcoanos. Tal vez, la concordia de 1430, además de por las propias disensiones entre los parzoneros, pudo venir provocada por la presión de los Parientes Mayores y de las capas sociales superiores, que desde comienzos del siglo $\mathrm{XV}$, comenzaron a usurpar -o lo intentaron- las tierras comunales, en un proceso que se dio en todo el territorio vasco, como ya se ha descrito.

También la Parzonería de Álava y Guipúzcoa estaba en una zona fronteriza y por ello tuvo problemas, viéndose obligada a llegar a acuerdos con los territorios limítrofes. En 1479 el Condado de Oñate -que hasta 1845 no se incorporó a la Provincia de Guipúzcoa- firmó una concordia con la Parzonería, en torno a los derechos sobre los montes de Urbía y Olza, en la parte occidental de la Parzonería. Como consecuencia del crecimiento experimentado por la población y las actividades productivas de Oñati -se constata una gran cantidad de roturaciones a lo largo del XV, en detrimento del bosque $^{59}$-, los recursos de la zonas de montaña cercanas se convierten en estratégicos para los vecinos del señorío, por lo que trataran de ampliar sobre ellos su zona de aprovisionamiento, más aún teniendo en cuenta que hasta comienzos del XV eran tierras

58. URZAINQUI, Asunción: La comunidades...op. cit., pp. 38-39; Idem: «Los montes públicos guipuzcoanos», Lurralde, 10 (1987), pp. 175-184.

59. UGARTE, Félix María: «Los seles en el Valle de Oñate», BRSBAP, XXXII, 3-4 (1976), pp. 447-510. 
de realengo, lo que equivale a decir, que son tierras de nadie y de todos. De hecho, los vecinos de Oñate acostumbraron hasta finales del siglo XV a pastar con su ganado en estos montes, a tener sus chabolas y albergaderos y a extraer leña y madera «...para los torneros, asteros y otros oficiales, para hacer taradores, escudillas, é astas é otras cosas...». Para acabar con los conflictos entre la Parzonería y el Condado de Oñati, una serie de jueces árbitros elegidos por las tres partes (Salvatierra, Segura y Oñati) establecieron una sentencia arbitraria el 16 de noviembre de 1479, por la que se permitía a los vecinos de Oñati disfrutar de las hierbas, pasto y aguas, pero de «sol a sol», sin poder hacer cabañas o albergaderos, y cortar leña y madera para abastecer a sus oficios, pero sin reciprocidad por parte del Condado; es decir, no se contemplan los mismos derechos de los vecinos de la Parzonería en los montes de Oñati ${ }^{60}$.

Las relaciones entre la Parzonería de Álava y Guipúzcoa y el valle de la Burunda en torno a los montes mencionados serán muy conflictivas, a causa de la indefinición de las fronteras, y traducidas en robos de ganado y actos de bandolerismo. El acuerdo definitivo se produjo en 1516, posiblemente por el buen clima reinante entre ambas partes desde la conquista por parte de Castilla del reino de Navarra en 1512. Burunda y la Parzonería (la comunidad alavesa y guipuzcoana acuden cada una de forma individual) aceptan someterse al arbitrio de varios jueces. La sentencia dada por dichos jueces árbitros el 23 de junio, creaba la Parzonería de la Concordia, fijando de forma definitiva los límites y el aprovechamiento de dichos montes. Únicamente serán comunes el aprovechamiento de hierbas, pasto y aguas, para todo tipo de ganado, excepto para el porcino, mientras que en el resto el aprovechamiento corresponderá a cada parte de forma individual. En el caso de las hierbas y aguas, el aprovechamiento será de «sol a sol», es decir, los ganados deberán volver a sus propios términos al anochecer ${ }^{61}$.

No obstante, será a partir del siglo XVI cuando se vaya conformando la Comunidad de montes, esto es, una entidad con sus estructuras, lugar de reunión y su personal de vigilancia. Serán Segura y Salvatierra las que ostenten la jurisdicción sobre esos montes durante el siglo XVI. Desde 1616, también Cegama, Cerain e Idiazábal -cuando consigan desgajarse de Segura y obtener su propio villazgo-, compartirán dicha jurisdicción con las dos grandes villas. Ello será posible tras superar la conflictividad con las comunidades vecinas y tras definir claramente el territorio que pertenece a la Parzonería. Las villas se reunían para gestionar los montes, como copropietarios de los mismos. El producto de montes se dividía, correspondiendo la mitad del valor a la Parzonería de Álava (la mitad para Salvatierra y la otra mitad entre San Millán y Asparrena) y la otra mitad a la de Guipúzcoa (la mitad para Segura y la otra mitad entre Cegama, Cerain e Idiazábal) $)^{62}$.

60. ArAgón RuANO, Álvaro: «Gestión, uso y aprovechamiento...op. cit., pp. 86 y A. Parz., A, 5, 1, 2.

61. Ibidem, pp. 85-86.

62. ARAGÓN RUANO, Álvaro: El bosque guipuzcoano...op. cit., pp. 51. 


\section{CONCLUSIONES}

La formación de comunidades de montes se produjo en un momento y circunstancias concretas. La mayor parte de las comunidades iniciaron su andadura en el siglo $\mathrm{XV}$, momento de clara expansión demográfica y productiva, que coincidió con la necesidad por parte de las entidades municipales de consolidar y definir su territorio, en un intento por blindar sus recursos naturales frente a la rapacidad, usurpación y ansias de entidades circunvecinas y particulares, y como consecuencia de su propio crecimiento administrativo y burocrático. Los mencionados procesos provocaron asimismo cambios en el modelo de hábitat y de ocupación del territorio, cuya expansión venía -y seguirá desarrollándose de igual modo en los siglos posteriores ${ }^{63}$, lo cual provocará la formación de nuevas comunidades y el amojonamiento de los límites, como les sucedió a Fuenterrabía y Oyarzun en 1750 o a Oñate, Escoriaza y Arechavaleta en $1759^{64}$ - aplicándose sobre el terreno siguiendo un esquema centrífugo, ganando paulatinamente altura.

En este sentido, creemos poder aseverar que la formación de comunidades y la consecuente delimitación de los límites juridiccionales suponen el punto final de un proceso de consolidación y definición de una serie colectividades de hábitat, territoriales, jurisdiccionales y políticas -aunque en algunos casos se prolongará en el tiempo hasta el siglo XVII y XVIII- que comenzaron su andadura, al menos documental, en los valles del siglo XI, y que dieron lugar al conjunto de lugares y repúblicas, ciudades, villas, alcaldías mayores, universidades y aldeas que conformaron durante la Edad Moderna la Provincia de Guipúzcoa.

La formación de comunidades de montes es una consecuencia de ese proceso, derivada de las necesidades cada más amplias de unas instituciones como las municipales que, al calor del amparo regio, se fueron consolidando y fortaleciendo desde el siglo XII. Por supuesto, no fue ni mucho menos el último episodio de un fenómeno que aún en la actualidad se sigue produciendo, con episodios como el de la Población de Igueldo, antigua universidad, adscrita a San Sebastián.

Con todo, la formalización de convenios y concordias, que dieron lugar a la formación de comunidades de montes, sirvieron desde el momento de su firma como punto de referencia y marco legal de convivencia para los vecinos y moradores de los territorios que compartían frontera. La existencia de un marco legal, sin embargo, no significa que su articulado se respetase y cumpliese al pie de la letra. En realidad, la

63. En el caso concreto de Irún, si hasta 1766 la mayor parte de los caseríos se situaban en llano y vega, a partir de la misma fecha cada vez son más numerosos los caseríos de nueva edificación en ladera, colina o monte, sobre todo en el período entre 1791 y 1845. De hecho, de los 207 caseríos mencionados para 1766 sólo 2 superan los 200 metros de altura, mientras que de los 109 de nueva fabricación entre 1791 y 1845 ya son 12 los que superan los mencionados 200 metros de altura, y muchos de ellos se sitúan ahora en el barrio de Bidasoa, geográficamente más alejado del núcleo de población (URRUTIKOETXEA LIZARRAGA, José: «En una mesa y compañia». Caserio y familia campesina en la crisis de la «sociedad tradicional». Irún, 1766-1845, San Sebastián, 1992, pp. 291-298).

64. ArAgón RuANO, Álvaro: El bosque guipuzcoano...op. cit., p. 51. 
conflictividad continuó, ya que las concordias eran sistemáticamente transgredidas, pero al menos existía una referencia legal para perseguir dicho comportamientos. La redacción de concordias, al menos, estableció un código deontológico y moral, que permitió que la conflictividad entre diferentes colectividades humanas y jurisdiccionales se mitigase en fuerza y periodicidad; los conflictos ya no fueron tan enconados ni tan habituales, sobre todo teniendo en cuenta que, en algunos casos, previa formalización de los acuerdos, había habido muertes y destrucciones. 